\title{
Komponen Biaya Pelayanan Jasa Kapal TugBoat Voyager 12 pada PT Spectra Tirta Segara Line Cabang Cirebon
}

\author{
Indriyani ${ }^{1}$, Irene Dini $\mathrm{P}^{2}$ \\ ${ }^{1,2}$ Akademi Maritim Nusantara, Cilacap \\ indrip2cd11010@gmail.com
}

Diterima 13 Agustus 2021, direvisi 24 Agustus 2021, diterbitkan 06 Oktober 2021

\begin{abstract}
Abstrak
Penelitian ini memiliki tujuan mengetahui komponen biaya pelayanan kapal TB Voyager 12 Pada PT SpectraTirta Segara Line Cabang Cirebon. Penelitian ini merupakan penelitian kualitatif dengan melakukan pengumpulan data dengan metode observasi, wawancara dan studi pustaka. Analisis data menggunakan deskriptif kualitatif. Penelitian ini menunjukkan bahwa komponen biaya pelayanan kapal TB Voyager 12 selama di Pelabuhan adalah Biaya Labuh, Biaya Tambat, Biaya Tunda, Biaya Pandu, Koordinasi dengan Instansi-instansi di Pelabuhan, Biaya Transportasi, Telekomunikasi, dan Akomodasi, dan Penerimaan Negara Bukan Pajak Kantor Kesehatan Pelabuhan dan Radio Pantai, Biaya air tawar
\end{abstract}

Kata kunci : Komponen, Biaya, Pelayanan

\begin{abstract}
This study aims to determine the cost component of the TB Voyager 12 ship service at PT Spectra Tirta Segara Line Cirebon Branch. This research is a qualitative research by collecting data with the method of observation, interviews and literature study. Data analysis used descriptive qualitative. This study shows that the components of the cost of serving the TB Voyager 12 ship while at the port are the Anchoring Fee, Mooring Fee, Delay Fee, Scout Fee, Coordination with Agencies at the Port, Transportation, Telecommunication, and Accommodation Costs, and Non-Tax State Revenues from the Health Office. Harbor and Coastal Radio, Fresh water costs
\end{abstract}

Keywords: Component, Cost, Service

\section{Pendahuluan}

Jasa keagenan mempunyai peran dalam membantu kebutuhan kapal selama singgah di pelabuhan. Salah satu agen yang berperan dalam kedatangan dan keberangkatan kapal di Pelabuhan Cirebon adalah PT Spectra Tirtasegara Line. Kegiatan perusahaan tersebut adalah mengageni kapal, mengurus perizinan dan dokumen angkutan laut beserta keperluan kapal, kontrak angkutan laut, sewa tug boat dan tongkang baik di dalam negeri maupun di luar negeri, menangani proses kedatangan dan keberangkatan kapal, bongkar muat barang antar pulau seperti barang - barang proyek dari Pulau Kalimantan dan Batubara
Dalam menjalankan kegiatan keagenan kapal, ada beberapa biaya yang diurusi oleh agen. Menurut Mulyadi (2015:8) Biaya adalah suatu sumber ekonomis yang dapat diukur dalam satuan uang yang dikorbankan untuk tujuan tertentu [1]. Sedangkan biaya kapal merupakan biaya yang ditimbulkan dalam pengoperasian suatu kapal baik untuk kebutuhan kapal maupun anak buah kapal.

Perusahaan yang menggunakan jasa angkutan laut pasti mengeluarkan ongkos angkut dalam pengiriman barangnya. Menurut Wakil Ketua Umum Indonesian National Ship Owner Association (INSA) terdapat delapan komponen biaya pelabuhan di Indonesia yaitu 
biaya pemuatan dan pembongkaran (stuffing dan stripping), biaya penumpukan di depo menunggu dimuat ke kapal, biaya pemindahan kontainer dari depo ke lapangan penumpukan (container yard), biaya pemindahan kontainer dari lapangan penumpukan ke lapangan penumpukan lain untuk muatan ke kapal, biaya menaikkan/menurunkan kontainer kosong/isi, biaya pemanduan kapal untuk bersandar dan keluar pelabuhan, biaya pemindahan kontainer dari lapangan penumpukan ke lambung kapal, biaya pemakaian dermaga dan kebersihan[2] Sedangkan menurut Djunuda (2017) pelayanan kapal selama di pelabuhan Nusantara dan Cappa Ujung Parepare meliputi pelayanan pandu, pelayanan tambat, pelayanan tunda dan pelayanan air. [3].

Penelitian ini ingin mengetahui komponen $\begin{array}{lll}\text { biaya TugBoat } & \text { Voyager } & 12\end{array}$ yang diageni oleh PT Spectra TirtaSegara Lines saat singgah di pelabuhan kelas II Cirebon pada tanggal 26 Januari 2021 sampai dengan 30 Januari 2021.

\section{Materi dan Metode}

Menurut UU No.17 Tahun 2008 Tentang Pelayaran terdapat beberapa tarif pelayanan jasa kapal yaitu tarif jasa labuh, tarif jasa tambat, tarif jasa pemanduan dan tarif jasa penundaan[4]. Biaya kapal selama di pelabuhan yang ditimbulkan karena kegiatan kapal masuk maupun kapal keluar, meliputi persiapan sebelum kapal masuk ke pelabuhan, sandar kapal, kegiatan pembongkaran pemuatan dan kapal keluar dari pelabuhan.

Ada beberapa jenis biaya di pelabuhan yaitu :

\section{Biaya Labuh}

Uang labuh dikenakan terhadap kapal yang memasuki daerah perairan pelabuhan selama jangka waktu tertentu. Dibedakan antara pelayaran luar negeri dengan pelayaran dalam negeri. Uang labuh dipungut atas dasar isi kotor dalam GRT / 15 hari untuk meningkatkan frekuensi kunjungan kapal, karena uang labuh yang diperhitungkan adalah hanya pada kunjungan pertama dalam 15 hari.

Biaya Tambat
Uang tambat dikenakan terhadap kapal yang melakukan tambat (dari mengikat tali sampai dengan melepaskan tali), kapal tertambat besi, kayu, beton, pelampung dan kapal tersebut merapat pada kapal lain yang sandar

\section{Biaya Tunda}

Tarif atau biaya yang dikenakan terhadap pada kapal dikarenakan kapal memerlukan penundaan untuk pertimbangan keselamatan pelayaran. Penundaan ini di wajibkan pada kapal dengan panjang lebih dari 70 meter

\section{Biaya Pandu}

Biaya pandu atau tarif yang dikenakan pada kapal yang GRT-nya lebih dari $150 \mathrm{~m}$ dan diberlakukan satu kali gerakan masuk dan satu kali gerakan keluar

\section{Metode Pengumpulan Data}

Jenis data dalam penelitian ini adalah data primer dan data sekunder.

Pengumpulan data primer dilakukan dengan melakukan wawancara terhadap pihak pelabuhan cabang Cirebon dan pemilik kapal/agen tentang komponen biaya operasional pelayanan kapal, melakukan pengamatan secara langsung kegiatan kapal selama di pelabuhan

Data sekunder dilakukan dengan cara studi pustaka. Studi pustaka untuk memperoleh ukuran kapal yang masuk ke pelabuhan, tonase Kapal (GT kapal), tarif pelayanan kapal yang berlaku saat ini.

\section{Metode Analisis}

Adapun langkah-langkah dalam menganalisis data yaitu sebagai berikut:

Menghitung pelayanan jasa kapal antara lain selama singgah di pelabuhan :

Biaya Labuh

Biaya Labuh perhitungan GRT kapal x 1 kali kunjungan $\mathrm{x}$ tarif Rp.84.

Biaya Tambat

perhitungan GRT kapal x 3 hari x tarif Rp. 150).

Biaya Tunda

Perhitungan ( GT x tarif variabel ) + biaya tetap ) $\mathrm{x}$ jam ) 
Biaya Pandu

Biaya dihitung dengan rumus tarif tetap + ( tarif variabel x GT )

Data yang disajikan dalam penelitian ini dianalisis dengan metode deskriptif kualitatif

\section{Hasil dan Pembahasan}

Biaya pengurusan kapal merupakan biaya yang timbul karena kebutuhan kapal ataupun kepentingan crew kapal dalam kebutuhan yang diperlukan sebelum kapal sandar dan sesudah kapal berangkat.

Biaya di pelabuhan merupakan karena kegiatan kapal masuk maupun keluar dari suatu pelabuhan. Baik mengenai persiapan sebelum kapal itu masuk kepelabuhan dilanjutkan pada saat kapal sandar di dermaga dan selesai melakukan bongkar muat barang dan kemudian meninggalkan pelabuhan

Sebelum kapal sandar maka pihak kapal akan memberitahukan keperluan kapal pada pihak agent. Maka dari itu pihak agent membuat penghitungan biaya sesuai apa yang diminta dari pihak kapal, biaya-biaya yang diperlukan antara lain :

\section{a. Biaya Labuh}

Berdasarkan rumus penghitungan biaya labuh kapal TB Voyager 12 yaitu GRT kapal x 1 kali kunjungan $\mathrm{x}$ tarif $\mathrm{Rp} 84$, maka penghitungannya sebagai berikut ;

4.447 GT x 1 x Rp.84 = Rp. 373.548 ,

Jadi biaya labuh kapal TB Voyager 12 selama berlabuh di pelabuhan Cirebon adalah sebesar Rp 373.548,-

Biaya labuh adalah biaya yang dikenakan kepada kapal dikarenakan penggunaan sarana pelabuhan selama jangka waktu tertentu . Uang labuh dipungut atas dasar isi kotor dalam GRT / 15 hari dari jumlahnya relatif kecil. Besaran biaya labuh yang sedikit diharapkan meningkatkan minat pemilik kapal untuk berkunjung di pelabuhan kelas II Cirebon karena penghitungan uang labuh dihitung pada 15 hari pada saat kapal pertama berkunjung.

\section{b. Biaya Tambat}

Biaya tambat dihitung dengan rumus GRT kapal x 3 hari x Tarif Rp 150,-, maka penghitungannya sebagi berikut

4.447 GT x 3 hari x Rp 150, - = Rp 2.001.150,-
Jadi biaya tambat kapal TB Voyager 12 selama berlabuh di pelabuhan Cirebon adalah sebesar Rp 2.001.150,-

Biaya tambat dikenakan pada kapal yang bertambat dan melakukan tambat mulai dari mengikat sampai dengan melepaskan tali.

\section{c. Biaya Tunda}

Biaya penundaan dihitung dengan rumus ( GT $\mathrm{x}$ tarif variabel ) + biaya tetap ) $\mathrm{x}$ jam )

Maka perhitungannya sebagai berikut

( 4.447 GT x 90 ) + Rp 3.600.000,- ) x 2,5 jam $=\operatorname{Rp} 9.400 .230$,-

Tarif jasa penundaan untuk kapal angkutan laut dalam negeri berbendera asing dan kapal laut luar negeri mengikuti tarif yang berlaku di pelabuhan umum Cirebon.

Perhitungan penagihan pelayanan penundaan dihitung dengan 2,5 jam ( 1,5 jam pelayanan ditambah 1 jam mobilisasi per Gerakan. Kapal memerlukan penundaan dengan adanya pertimbangan keselamatan pelayaran.

\section{d. Biaya Pandu}

Biaya dihitung dengan rumus tarif tetap + ( tarif variabel x GT )

Maka perhitungannya sebagai berikut

Rp.1.050.000,- + ( 60 x 4.447 ) = Rp 1.316.820,- per Gerakan, apabila kapal melakukan 2 kali gerak kapal masuk dan kapal keluar maka biayanya menjadi $\operatorname{Rp} 2.633 .640$

Tarif jasa pemanduan untuk kapal angkutan laut dalam negeri berbendera asing dan kapal laut luar negeri mengikuti tarif yang berlaku di pelabuhan umum Cirebon.

e. Biaya Koordinasi dengan Instansi-instansi terkait di Pelabuhan

Biaya yang diperlukan pihak agent untuk keperluan di Kantor Kesyahbandaran dan Otoritas Pelabuhan dan untuk menyampaikan tugas dan fungsinya Biaya keperluan untuk mengajukan permohonan tempat sandar kapal kepada PELINDO II. Agent meminta informasi kepada kepanduan kapan tanggal dan jam berapa kapal disandarkan atau diberangkatkan agar pihak kapal mempersiapkan segala sesuatu yang dibutuhkan. Sebagai pengendali atau pengawasan dalam segala kegiatan yang ada dipelabuhan dan bertanggungjawab atas segala hal yang ada.

Biaya untuk pengecekan kesehatan dari Petugas Kantor Karantina Kesehatan Pelabuhan. Petugas Kantor Karantina Kesehatan Pelabuhan melaksanakan 
pencegahan masuk dan keluar penyakit karantina dan penyakit menular wabah, karantina, melayani kesehatan terbatas di wilayah kerja pelabuhan, serta pengendalian dampak kesehatan lingkungan.

Dalam mengembangkan tugas, Karantina Kesehatan Pelabuhan melaksanakan fungsi, antara lain :

Biaya untuk petugas pemandu kapal yang akan masuk ke dalam pelabuhan, bila Nahkoda belum tahu lokasi tempat kapal disandarkan.

Biaya Penerimaan Negara Bukan Pajak pada Stasiun Radio Pantai, untuk memberi informasi tanggal kedatangan kapal.

Biaya keamanan untuk Satpolairud, Keamanan Laut Angakatan Laut, Kepolisian Pelabuhan dan Kesatuan Penjagaan Laut dan Pantai memberitahukan kedatangan kapal.

f. Biaya Transportasi,Telekomunikasi, dan Akomodasi

Dalam pengurusan biaya diperlukan adanya transportasi, telekomunikasi, dan akomodasi untuk memperlancar dalam pengurusan kapal.

Biaya transportasi, transportasi sarana yang digunakan untuk berkunjung dari kantor, ke pelabuhan dan ke kapal dengan menggunakan kendaraan dalam kegiatan kapal di pelabuhan.

Baya telekomunikasi, telekomunikasi sarana yang digunakan untuk berkomunikasi dengan menggunakan Telephone/Hp untuk berkoordinasi dengan petugas, owner kapal dan pihak kantor dalam penyandaran dan urusanurusan lainnya. Biaya akomodasi digunakan dalam suatu kondisi atau proses dalam menyelesaikan masalah yang terjadi permasalahan yang ada.

g. Penerimaan Negara Bukan Pajak Kantor Kesehatan Pelabuhan dan Radio Pantai

Surat Persetujuan Berlayar Karantina Kesehatan Pelabuhan (SPB-KKP) biaya tagihan atas pemeriksaan kapal bahwa bebas sanitasi (Ship Sanitation Control Exemption). Dari Karantina Kesehatan Pelabuhan memeriksa anak buah kapal di tengah laut agar memastikan semua crew kapal sehat dan memeriksa kebersihan di dalam kapal agar pihak Kantor Kesehatan Pelabuhan membuat sertifikat Karantina Kesehatan Pelabuhan.

Penerimaan Negara Bukan Pajak Radio Pantai Vassel Traffic Services pengiriman berita kapal kestasiun radio pantai, untuk memberikan mengenai tanggal dan jam kedatangan kapal di pelabuhan. h. Biaya air tawar

Biaya ini merupakan biaya air tawar per ton dikalikan harga air tawar,

Gambar 1. Komponen biaya

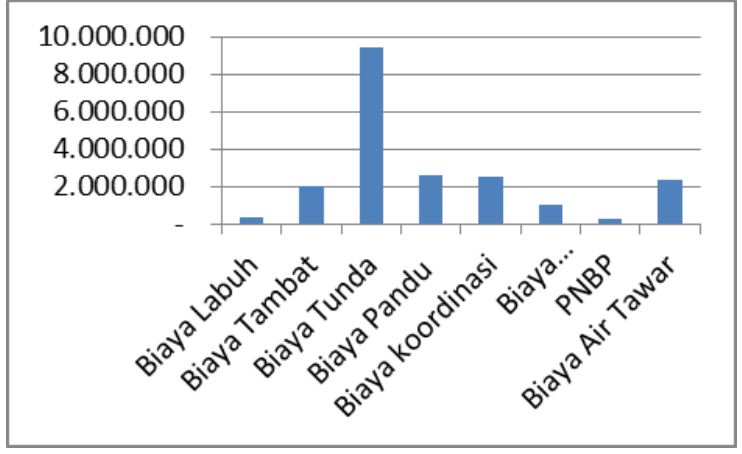

Berdasarkan gambar diatas terdapat delapan komponen biaya yang dikeluarkan TB Voyager 12 selama singgah di Pelabuhan kelas II Cirebon, biaya yang tertinggi adalah biaya tunda dan yang terendah adalah biaya labuh. Besaran biaya dipengaruhi oleh GRT kapal, waktu lamanya kapal singgah di pelabuhan dan sarana prasarana pelabuhan yang dibutuhkan kapal selama singgah di pelabuhan.

\section{Kesimpulan}

Komponen biaya pengurusan kapal tugboat voyager 12 pada PT. Spectra Tirtasegara Line Cabang Cirebon adalah Biaya Labuh, Biaya Tambat, Biaya Tunda, Biaya Pandu, Koordinasi dengan Instansi-instansi di Pelabuhan, Biaya Transportasi, Telekomunikasi, dan Akomodasi, dan Penerimaan Negara Bukan Pajak Kantor Kesehatan Pelabuhan dan Radio Pantai, Biaya air tawar.

\section{Ucapan Terima Kasih}

Penulis mengucapkan terima kasih pada Akademi Maritim Nusantara Cilacap, PT Spectra Tirta Segara Line Cabang Cirebon yang mendukung penelitian ini.

\section{Daftar Pustaka}

[1] "Mulyadi.2015.Akuntansi Biaya. Edisi 5, Yogyakarta: Sekolah Tinggi Ilmu Manajemen YKPN".

[2] R. Djunuda, P. Pascasarjana, and U. Hasanuddin, the Study of Ship Service Tariff. 2017. 
[3] J. S. Vol, "Komponen Penentu Biaya dalam Penetapan Freight Cost Di PT Global Marine Jakarta Indriyani , Frilia Esti Anggraeni Akademi Maritim Nusantara," vol. 3, no. 2, 2019.

[4] Undang-Undang 17 Republik Indonesia, "UU 17 tahun 2008 tentang Pelayaran," Vis. Comput., vol. 24, no. 3, pp. 155172, 2008. 